\title{
The Virtual Health University: An elearning Model within the Cuban Health System
}

\author{
José B. Jardines Méndez, MD, MEd
}

\begin{abstract}
This paper describes Cuba's experience with the Virtual Health University (VHU) as a strategic project of INFOMED, promoting creation of an open teaching-learning environment for health sciences education, through intensive and creative use of Information and Communication Technologies (ICTs) and a network approach to learning.
\end{abstract}

An analysis of the VHU's main antecedents in its different stages of development provides insight into the strategic reasons that led to the establishment of a virtual university in the national health system during Cuba's so-called Special Period of economic crisis.

Using the general objectives of creating, sharing, and collaborating which define the VHU's conceptual-operative framework, the three essential components (subsystems) are described: pedagogical, technological, and managerial, as well as the operative stages of educational design, technological implementation, and teaching-administrative management system.

Each component of the model is analyzed in the context of global, modern university trends, towards integration of the face-to-face and distance education approaches and the creation of virtual institutions that assume the technological and pedagogical changes demanded by eLearning.

Keywords: TIC; eLearning; telehealth; medical education; INFOMED

moved from social needs and makes limited use of scientific and technological advances in education, as well as innovative approaches, which adopt the strengths of other models and aim to respond with quality and relevancy to the changes imposed by society and ICT development.

The traditional model has undergone various changes, from the behavioral model of Ralph Tyler (1949) that advanced the idea of objectives as the core of any curriculum, to that of Robert Pager (1962) that referenced specific objectives, to Popham-Baker's model (1970) that incorporated an evaluation of objectives to assess the level of incoming students, and Hilda Taba's model (1974) that provides a logical and methodological organization for content and associated learning activities.[2]

Nevertheless, it is necessary to develop a model that maintains the most important contributions of existing models while incorporating networking into the spatial-temporal dimension of the teachinglearning process from the didactic planning stage. This should be based on the learning module - not the content - and should prioritize the intensive, creative, and intelligent use of communication and collaboration tools.

The introduction of ICTs into the university modern-

\section{INTRODUCTION}

The 21st century challenge for education is to establish a new type of education based on the principles of excellence, quality, and relevancy, while integrating this education into production and service processes, placing emphasis on active and collaborative learning supported by Information and Communication Technologies (ICTs).

However, contradictory as it may seem, the challenge is not only technological, since it essentially requires a paradigm shift in the teaching-learning process itself, in a society where spatial-temporal relations are modifying the way we communicate.

The development of the Internet, and specifically of efficient tools for communicating and interacting, makes collaborative eLearning possible and increasingly supports face-to-face teaching processes. This new formative dimension is converting traditional teaching aids into learning tools, as well as transforming the dynamics and communication of the process.[1]

Several education models are currently in use in today's Information Society. These include the traditional model, which is re- ization process is a strategic reality transforming the traditional educational paradigm, and offering pedagogic alternatives never before available that include a different educational structure, distance-learning methodology, and the use of a wide range of technological and communication tools. All this is characterized by a flexibility that allows greater individual autonomy and creates possibilities to educate in a creative, critical, and participatory way that enables students to become dynamic agents of change.[3]

In this context and with the challenges currently faced by education in the Information Society, INFOMED, the national healthcare and telecommunications network and portal, launched the Virtual Health University (VHU). This paper presents an overview of the $\mathrm{VHU}$, details the theoretical-methodological concept behind it, and discusses the components characterizing its eLearning approach.

\section{BACKGROUND}

During the 1990s, Cuba's National Medical Sciences Information Network faced a sharp reduction in financial resources that dramatically affected the capacity to render information services through traditional means. This is when the country entered a 
critical phase of the so-called Special Period. Most of the subscriptions to international journals were suspended and national publishing was seriously affected as well.

In 1992, administrators at the National Medical Sciences Information Center (CNICM according to its Spanish acronym) initiated development of a Cuban telematics network with its node at a Havana medical school campus. Its goal was to facilitate access to information and knowledge within the National Health System (NHS), prioritizing primary care. Incrementally, the different institutions and health, teaching, and research professionals around the country were incorporated into this network called INFOMED (www.sld.cu).

INFOMED was created in response to a crisis, but at the same time it signified a leap forward, since it recognized the future of virtual health information access. From the beginning, this network required the use of email and other network services to collect and disseminate information.

Thereafter, the introduction and development of new information and communication technologies became increasingly commonplace in the NHS, acknowledging the importance of networks in problem solving, while placing human beings at the heart of the strategy.

Since the institutions responsible for health care, medical education, health surveillance, and health research and information belong to the NHS and the INFOMED network, several related areas were prioritized. These included: the education and communication sectors, and acquisition and introduction of new ICTs for them; training of human resources for efficient application and use of ICTs for health; connecting all health institutions to the network; and transforming the network into a true interactive space for developing new knowledge and values. This last was the most important and difficult challenge.

In practice, establishing and growing the network encouraged adoption of these actions, and laid the groundwork for more recent innovation efforts and further integration of the strategy. Development of the scientific information network and launch of the Cuban Virtual Health Library, made it necessary to design a strategy to create a virtual university that would lend itself to the development of INFOMED's capacity-building dimension.

\section{Creation and Formalization (1997-2000)}

The creation of the Virtual Health University (www.uvs.sld.cu) was approved by the Board of Rectors and Deans of the Higher Medical Education Centers during the 1996-1997 academic year. More than 4 decades of accumulated health teaching, research, and practice and the ongoing training of human resources for health, together with the existence of INFOMED, were the main reasons, strengths, and drivers behind the establishment of a Virtual University dedicated to excellence, academic quality, and social relevance.

The VHU basically emerged as a system of teaching programs that allowed courses to be conducted and distributed by email, using both quasi-present and distance learning modalities. A strategy was developed that recommended face-to-face meet- ings whenever possible, organized by the Higher Medical Education Centers (HMECs), to support the distance program and facilitate academic certification.

In this first stage, the VHU prioritized planning and organizing the distance education system by training professors and tutors at provincial workshops. At the national level, representatives from different medical schools around the country agreed on a curriculum strategy, teaching programs to prioritize, the preparation of teaching materials, and the type of technologies to use.

Starting with the 1998-1999 academic year, distance courses were conducted via email at the provincial level. In academic year 1999-2000, the VHU was officially approved by Ministerial Resolution 44/2000 as a national virtual institution for postgraduate education for professionals and technicians working in the NHS.

\section{Dynamic Web and Interaction (2001-2007)}

In the First Council of VHU Professors held at the end of 2000, participants concluded that with more than 200,000 health professionals and technicians working mainly in primary care, combined with transportation and other limitations, Cuba could not provide the necessary continuing education through traditional postgraduate methods.[4] Since collaborative, online work had already been identified as a priority, authorities decided to situate the Virtual Health University on the Internet, giving access to academic activities and services relevant to clinical practice and research.

In January 2001, the VHU site was officially launched. For the first time, modern technologies were incorporated into INFOMED allowing for an interactive, dynamic, and accessible site with teamwork tools. This enabled the development of a virtual institution that integrated technological, pedagogical, and managerial facets with class attendance, teaching, and research aspects.

From simple email courses, the program developed into an Internet space where participants could share and access the courses and develop new Web services. In this way, a more sophisticated technological environment was created, and priority shifted to training professors, students, and other potential VHU participants.[5]

Beginning in 2005, the project gained momentum, when 444 polyclinics around the country were gradually equipped with 2 to 4 networked computers each, to access the Virtual Library and University and other INFOMED services.[6] A process dedicated to accelerating public health eLearning (particularly in primary care) was launched. An in-depth study of the theoretical-methodological approach and education strategy of the VHU was undertaken, to lay a pedagogical and technological foundation for the model.

\section{APPROACH \& OBJECTIVES}

The Virtual Health University is a virtual teaching institution of the National Health System, co-administrated by the National School of Public Health and the National Medical Sciences Information Center. Its Governing Board is composed of representatives from various national health institutions, an academic network with teaching departments at the 4 Higher Medical Sciences Institutes, the Latin 


\section{Original Scientific Articles}

American Medical School, the provincial medical schools, and 4 dental schools around the country, plus a network of institutions (teaching, clinical care, research, and reference), where academic programs and other learning activities are carried out.

The general objectives of its conceptual and operative framework are to:

1. Create learning information resources and tools that enable efficient development of educational processes for the health sciences.

2. Share the best learning experiences and resources.

3. Collaborate with faculty at health sciences universities to create and develop learning resources, methodologies, and tools.

From these objectives, the VHU's Networked Learning Model (NLM) focused on three educational approaches used for the different processes and actions performed:

- Scientific-technical - according to the educational and scientific nature of the activities.

- Ethical-humanistic - concerning the creation of values and ethical principles.

- Information and knowledge management - related to the development of information management capacities and competencies, and the generation of new knowledge.

Conceptually, the model shares the same contextual framework as the rest of Cuban medical education, specifically:

- Decentralization of teaching at all levels of the NHS, (mainly in primary health care), with high enrollment and wide geographical distribution, and

- Existence of INFOMED, with resources, services, and tools enabling use of ICTs in the teaching process.

The Virtual Health University's educational model is conceptualoperative, systemic, and divided into two dimensions:

The theoretical dimension (conceptual) on which the model is based, has 3 essential components (subsystems): pedagogical, technological, and managerial.

The practical dimension (operative), encompasses the strategies and procedures through which each subsystem of the

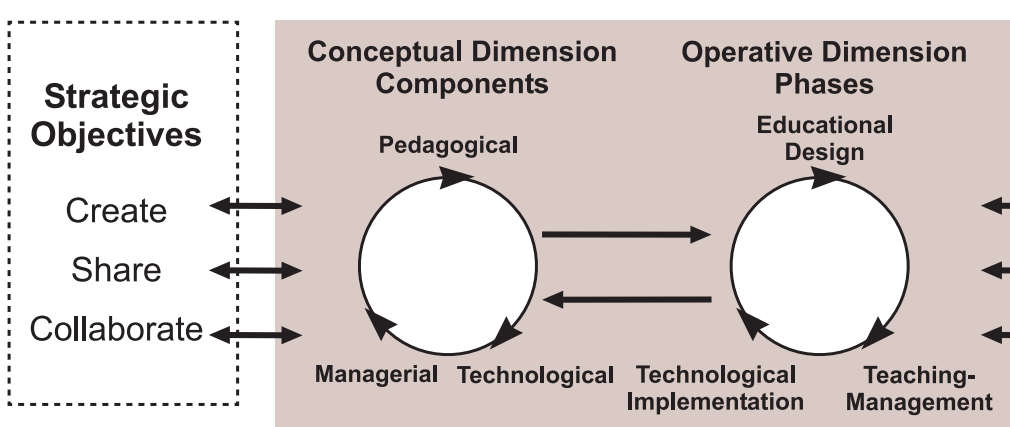

Figure 1: Virtual Health University - Network Learning Model

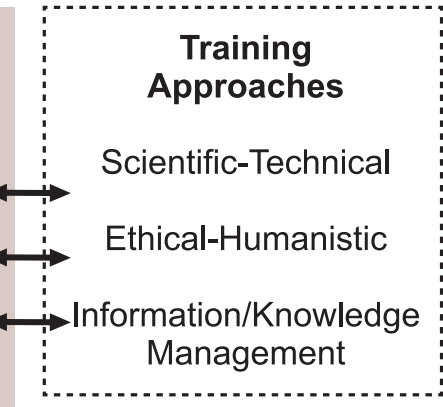

model functions. It is defined by three phases for creating and developing educational processes: educational design, technological implementation, and teaching-administrative management (Figure 1).

\section{The Pedagogical Component}

The Networked Learning Model of the VHU reflects paradigm shifts currently underway in education, whereby the curriculum prioritizes a learning continuum - with importance placed on competencies attained rather than subjects completed. Furthermore, evaluation becomes a critical element of the teaching-learning process and ceases to be simply punitive or a factor in assigning grades.

The NLM grants maximum priority to learning modules, teacherstudent communication, interaction, and collaborative work, emphasizing the use of the latest information and communication technologies providing networking tools for students and professors.

The model promotes a problem-based learning (PBL) approach, with flexible content and customized access. This model lends itself to the use of case studies and allows for incorporating competencies and projects into curriculum design where the objective of each learning module - not the content - is the central element of educational design.

The learning unit, as the basic cell and integrating factor of the different components of the teaching-learning process, has three essential structural elements: content, interactivity, and evaluation. Learning units may form didactic units, which at the same time may also form modular units and/or courses, depending on the level of training. The objectives define content, level of interaction, and communication activities. These play a decisive role both in the students' active learning and in evaluation, which is defined as permanent feedback within the process of any educational modality (face-to-face, quasi-present, and distance).

Learning activities are mainly carried out face-to-face at family doctor offices, polyclinics, hospitals, in the research institutes, and medical schools, with active participation by health professors and professionals. According to the modality, activities such as lectures, studies of clinical cases, discussion forums, etc., are scheduled by VHU and INFOMED, under the tutorship of appointed professors.

At the Virtual Health University, ICTs are used to launch educational strategies, not the other way around, taking advantage of their immense potential to promote more effective learning and develop more efficient educational services with quality, relevance, and universality in a new learning environment. This student-centered educational model integrates both face-toface and virtual components, and emphasizes a networking approach that 
allows for more interaction during the teaching-learning process between students and professors. In addition, it allows each student to set their own learning rhythm. Self-management and collaboration promote active learning in an open environment, in which the professor goes from information communicator to facilitator (tutor) and designer of the teaching-learning process (Figure 2).

Figure 2: Pedagogical Component of the Virtual Health University (VHU)

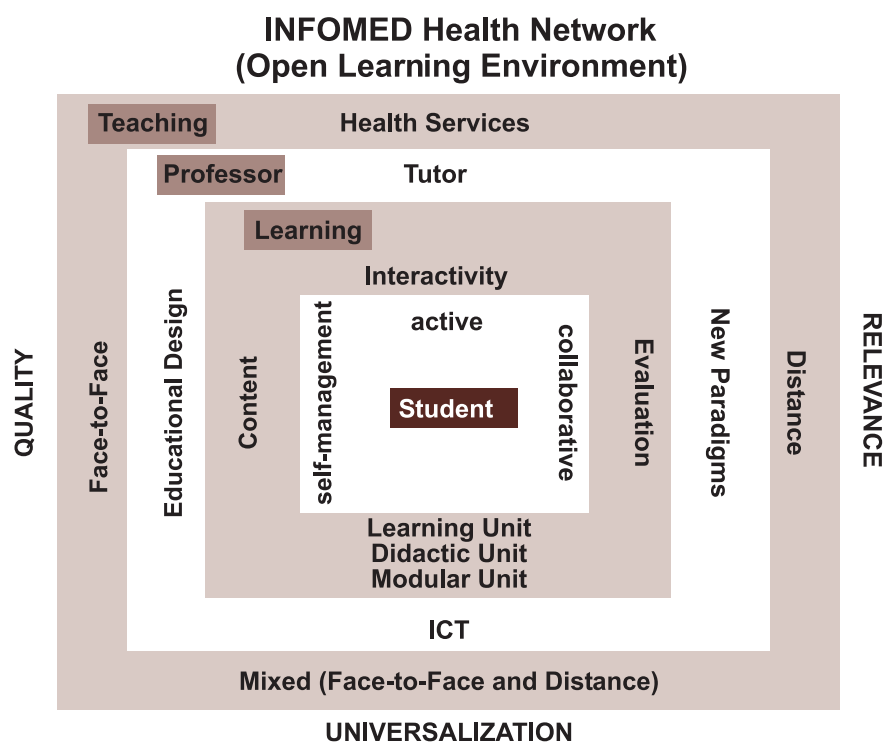

The educational design as a process (commonly known as instructional) includes not only instructional, but also educational aspects. The NLM defines a specific methodology for the learning plan and design and identifies the basic components of the teaching-learning process, specifically the learning units and their activities. This methodology was developed from experience gleaned during the development of the $\mathrm{VHU}$, and the international literature.[7-9]

The educational design phase consists of 6 stages:

1. Definition of teaching and technological options. Identifying learning needs, defining target audience, assessing human and financial resources and technological infrastructure available, so that feasible options for a successful instructional design can be decided.

2. General course design (general program). Defining the objectives, background, prerequisites, themes and content, and key words. First steps include deciding course structure and summarizing projected activities and strategies, as well as drawing up a course timeline and bibliography.

3. Course unit design. Designing learning, didactic, and modular units according to their different aggregation levels. The teaching strategy for each is defined, as well as content and calendar of activities, according to time available.
4. Interactive system design. Designing learning activities, their dynamics, sequence, resources, and tools to be used, as well as writing practical guides and other elements of teaching strategy, including the tutorship system, to ensure their proper implementation.

5. Feedback system design. Designing self-evaluation and other forms, including systematic and final course evaluations, to enable ongoing and interactive feedback during the teaching-learning process.

6. Final design and general information. Performing a final review of the entire course, allowing for final adjustments to the general program and individual course components (second and third stage), based on learning activities and evaluation designs developed in the fourth and fifth stages.

\section{The Technological Component}

Using open access software and ICTs of varying degrees of complexity, users become active producers and managers of information and knowledge. Other characteristics of the technological component used in the VHU's Networked Learning Model include interoperability and reusability of learning tools.

Other major characteristics include pro-active and intense use of INFOMED during the teaching-learning process, together with traditional teaching aids and technologies, such as educational software, video and television, in an open learning environment that favors integration of teaching activities, whether face-to-face or not, into health practice. The different content, services, and tools are organized in an open-ended manner, giving the educational process an interactive and independent character.

The NLM's technological implementation phase is directly related to the design and progress of the systems and tools comprising the VHU's architecture through three levels: technological support, data and information, and services (Figure 3).

Figure 3: Architecture of the Virtual Health University (VHU)

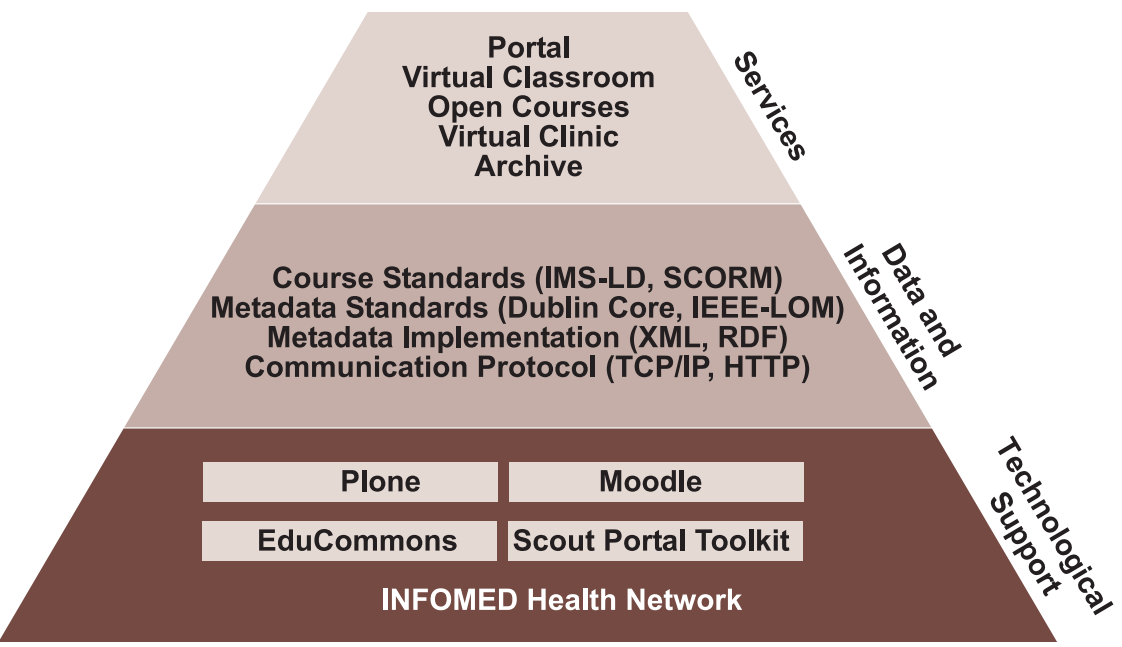

Legend: IMS-LD (Instructional Management System-Learning Design), SCORM (Sharable Content Object Reference Model), IEEE-LOM (Institute of Electrical and Electronics Engineers-Learning Object Metadata), XML (eXtensible Markup Language), RDF (Resource Description Framework), TCP/IP (Transfer Control Protocol/Internet Protocol), HTTP (HyperText Transfer Protocol) 


\section{Original Scientific Articles}

The first level is technological support. It has 4 main systems in INFOMED:

1. Plone (www.plone.org): Content Management System (CMS) - a collaborative environment that allows all users to become potential content producers depending on their roles.

2. Moodle (www.moodle.org): Learning Content Management System (LCMS) - supports the virtual classroom as a virtual learning environment.

3. EduCommons (http://cosl.usu.edu/projects/educommons): course management system (Open Course Ware System, OCWS) - used by the VHU to publish teaching materials in course format following the Massachusetts Institute of Technology (MIT) model.

4. Scout Portal Toolkit (SPT, http://scout.wisc.edu/Projects/ SPT): a metadata repository for referencing and searching VHU educational resources; allows resource collections to be shared via the Internet, relying on collections' intelligent metadata tools.[10]

The second level - data and information - in the VHU's architecture includes different internationally accepted communication protocols and eLearning standards, specifically the IEEE-LOM for Learning Object Metadata that permits interoperability among teaching and service institutions retrieving information.

The third level corresponds to over 25 services permitting health students, faculty, and professionals to be content producers and active participants as well as users. These services make possible an open, collaborative educational environment.

The VHU's Aggregator Portal, supported by Plone, enables access to various resources and services and to the communication and collaboration tools permitting interaction among students, professors, and users interested in the health field in general and health sciences education specifically. It facilitates communication and interaction, study and discussion of clinical cases, access to resources and services, and is used mainly for decentralized production of learning modules and other teaching materials.

Each time a user registers, a personal folder is created, permitting them to produce content and participate as creators in any part of the VHU. Currently, about 8,000 people are registered in the VHU, and there are 548 online professors, of whom 87 rank as experts, 121 are advisers, 257 are instructors and 83 are collaborators.[11]

During the 2006-2007 academic year, 22 national-level matriculation options were developed: 12 post-graduate courses, 3 certificate courses, 6 Master's Degree courses and 1 Doctoral course. Some $60 \%$ of students successfully completed the coursework.[12]

- Post-Graduate Courses: Medical Psychology, Research Methodology, Health Economics, Cardiopulmonary Resuscitation, and 8 Health Technology courses

- Certificate Courses: Health Information Management, Medical Education, and Atherosclerosis

- Master's Degree Courses: Medical Education, Health Economics, Atherosclerosis, Health Psychology, Public Health, Health and Aging
- Doctoral Course - Collaborative mentorship in Atherosclerosis

The Virtual Classroom (http://aulauvs.sld.cu), powered by Moodle, is the VHU environment producing Internet and Web-based courses, containing resources (in text or tab format, photos, diagrams, audio, video, Web pages or Acrobat documents, etc.), plus student activities (electronically submitted assignments, tests, surveys, forums, etc.). It is designed as an interactive learning space with formal and informal training activities, where interaction is defined by the activities and educational communication, rather than content.

A medium-term goal of the Virtual Health University is to ensure the interoperability of learning tools, independently of the eLearning platform used, to improve the training processes of Cuban medical universities (face-to-face, virtual, and/or mixed courses) by using the network to promote interaction and tutorials.

Since its creation, 238 courses have been offered at the Higher Medical Education Centers' level and 12 at the national level. Currently 160 courses are being developed, and more than 100 Supercourses in 28 fields have been published.[13]

Open Access Courses (www.uvs.sld.cu/cursosabiertos/) are a workspace for publishing teaching materials in course format (content archive). Based on the course management system EduCommons, this creates a special environment for creating and designing teaching-learning processes in the Virtual Health University by giving free, simple, and logical access to existing course collections. VHU open access courses create a collaborative space for professors and Cuban health institutions to access and share educational materials accessible in an open, decentralized way.

The Virtual Clinic (www.uvs.sld.cu/clinica/) is an interactive space that since its inception, has promoted access by, and integration of medical professionals into clinical areas through the Internet. It has 3 sections devoted to clinical cases: diagnostic discussions, clinical pathology discussions, and the newly-created section called case study - the latter designed primarily for undergraduates--allowing health professionals and students to share and interact on clinical cases and professional experiences of academic interest. These may be directly related to teaching methods or not. As its name indicates, the first section is a virtual space whereby institutions or individuals discuss cases of interest in order to render a definitive diagnosis online. The second section is dedicated to post-mortem discussions of pathologists' findings.

The case study section aims to strengthen use of networks in health sciences by enabling open and flexible learning through an interactive (virtual and face-to-face), problem-based method in which cases are published and evaluated.[14] This proposal arose from the International Medical Education Trust's (IMET 2000) call to organize an International Medical School Network and create a common space for knowledge sharing, capacity building, and the shaping of ethics based on a comprehensive curricular model - virtual and face-to-face - which would be flexible and dynamic enough to be adapted to local contexts.[15]

There have been 48 diagnostic and 8 clinical pathology discussions, with highest participation by family medicine specialists (7), 
followed by internal medicine (6), and gastroenterology (4). Experts received over 6,000 questions; 1,893 were answered by faculty, while participants reviewing case studies or addressing each others' questions answered the rest. Of the questions answered by faculty, 251 were published in the VHU.[16,17]

The Metadata Repository (www.uvs.sld.cu/repositorio/recursosuvs/) is a Scout Portal Toolkit-supported system allowing referencing and rapid, effective, and advanced searches of the VHU's educational resources. Just registering gives you the ability to incorporate new resources and be referenced in the archive.

To summarize, the VHU's technological component follows current Web 2.0 trends, characterized by the interactive and creative role played by users and the active and collaborative nature of Webbased learning.[18]

\section{The Managerial Component}

The VHU uses a cooperative and decentralized management model emphasizing integration of its resources, services, and tools using face-to-face, quasi-present and/or virtual teaching methods. These can be applied to any academic or service institution within the Cuban NHS and are based on system theory and the chief components of the GESEDUCA model (UNESCO 1994).[19]

Main characteristics include: participatory, teamwork-based; decentralized, with operational or project management decisions made at the institutional level; flexible, with a capacity for modification responding to changes within the teaching environment; and holistic, with a comprehensive view of the teaching-learning process, promoting cohesion of NLM components.

This managerial component has 4 elements integrating the VHU's strategic cycle into the management improvement cycle, responding to basic questions related to organizational management: vision, planning, operational management, and procedure quality.

1. Vision - The VHU vision is to become a learning network where people and institutions work together to develop health sciences competencies and capacities to facilitate information and knowledge management through networked interaction and learning. Furthermore, it is viewed as a Virtual Campus using a networked, open learning approach, based on real healthcare-related processes where the teaching, health care, and research institutions of the National Health System take part.

2. Planning - Strategies for implementing the $\mathrm{VHU}$ vision are:

- Construction and maintenance of a virtual space for online interaction, learning, and work for the development of technical and professional health competencies.

- Human resources training for efficient use and application of ICTs in the education and health fields.

- $\quad$ Strengthening training capacities of the academic institutions and health service providers.

- Integration and systematization of national health information and knowledge management efforts.

- Using ICTs for online education, based on connectivity and technical capacities at academic and health services institutions.
- Development of online teaching and work methodologies and tools appropriate to the needs of Cuban health institutions.

3. Operational management - Project management is an objective-based management model that allows separation of decisions and assignment of VHU resources and responsibilities by component (courses, image galleries, clinical discussions, etc.) within different academic and service institutions of the National Health System. Every project or operation has a person in charge who organizes and coordinates the necessary activities and commits to the expected results.

Management takes place at two levels. The first is curricular (Pedagogical Management), associated with the teachinglearning process and basic functions of faculty (educational design, selection and/or creation of resources, tutorial system, etc.). The second is institutional (Institutional Management), which deals with administrative and management processes, where leaders and managers participate at institutional and local levels (coordination of equipment, training in virtual learning environments, etc.).

4. Process quality - The application of follow-up, control, and evaluation systems to improve the quality of the program's process is accomplished through a critical analysis of the process itself, academic results, and services produced in the VHU.

Individual commitments made by participants in the teaching and management processes, surveys conducted among students, professors, users, focus groups, and other evaluation mechanisms, enable the establishment of quality improvement plans at institutional and curricular levels.

\section{CONCLUSIONS}

The Networked Learning Model (NLM) used by the Cuban VHU is based on a pedagogical-technological model facilitating integration of teaching activities, face-to-face or not, into health practice. Its resources and services represent an open, online learning environment characterized by interaction and independence.

One of the particularities of the model is its active and intense use of INFOMED, together with educational software, video, and television, without excluding other traditional teaching aids. Health faculty, students, and professionals cease to be simply readers of materials or "passive" users in the network, but rather have the capability to create, share, and collaborate in the production of educational resources.

As part of the health network, the VHU is an example of a Latin American country with limited resources making use of information and communication technologies for interactive communication and online learning in undergraduate and postgraduate health sciences programs.

As part of their strategic planning, the Higher Medical Education Centers should assess further implementation of the online learning model for postgraduate studies for both national and international graduates of Cuban medical schools. 1 - 


\section{REFERENCES}

1. Jardines JB. E-learning en Cuba: un ejemplo y un reto para la epidemiología cubana. Rev Cubana Hig Epidemiol 2005;43(1):17-51. Available from: http://scielo.sld.cu/scielo.php?script=sci arttext\&pid $=$ S1561-30032005000100001\&lng=es\&nrm=iso

2. ¿Que Es Un Modelo Educativo? Centro de Asesoría Pedagógica. Red Informática de la iglesia en América Latina [cited 2006 Nov 30]. Available from: http://es.catholic. net/educadorescatolicos/694/2418/articulo. php?id=22081

3. Salas R, Borroto E, Hernández A. Universidad sin fronteras; ¿mito o realidad?. Educ Med Sup 2000;14(1):21-41. Available from: http://scielo. sld.cu/scielo.php?script=sci_arttext\&pid=S0864$21412000000100004 \& \mid n g=e s \& n r m=i s o \&$ tlng=es

4. V Taller Nacional y Primer Claustro de Universidad Virtual. Convocatoria de la Junta de Gobierno de la UVS. La Habana: CENAPEM; 2000.

5. Jardines Méndez JB. La Gestión del Conocimiento en los Sistemas de Salud. Trabajo presentado en la V Conferencia Regional de Ciencias de la Información en Las Américas. La Habana; 2001. Available from: http://www.bireme.br/crics5/proceedings/Jardines/confcr\%7E1/sld001.htm

6. Urra P. Programa para el fortalecimiento del Sistema de Información Científico-Técnica de la Salud en Cuba: una respuesta a los nuevos escenarios. ACIMED 2005;13(3). Available from: http://bvs.sld.cu/revistas/aci/vol13_3_05/ aci02305.htm

7. Díaz J, Ramírez T. Un Modelo de Diseño Instruccional para la Elaboración de Cursos en Línea. México: Universidad Veracruzana; 2002.
Available from: http://www.uv.mx/jdiaz/Disenolnstrucc/ModeloDisenolnstruccional2.htm

8. Zavando S, Parra C. Guía para el Diseño de Cursos en Internet. INTEC-CHILE. Portal de tecnologías de Información, Jun 2000 [cited 2006 Aug 20]. Available from: http://www.portalti.cl/ self/visor/contenidos. asp? guid $=\{$ C519AEC1 65E9-485E-8241-9B0E9A296FFE $\} \& I D=2444$

9. Marqués P. Diseño instructivo de unidades didácticas [homepage on the Internet]. BarceIona: UAB. Facultad de Educación. Departamento de Pedagogía Aplicada; 2002 [updated 2006 Mar 14]. Available from: http://dewey.uab. es/pmarques/ud.htm

10. Scout Project Toolkit. Overview. Scout Project [homepage on the Internet; cited 2007 Aug 23]. Available from: http://scout.wisc.edu/Projects/ SPT/index.php

11. Universidad Virtual de Salud. Miembros de claustro docente. [homepage on the Internet cited 2007 Aug 27]. Available from: www.uvirtual2.sld.cu/claustro/docentes.php

12. Jardines, J.B. "El modelo de aprendizaje en red Experiencias de las UVS Cubana". XII Convención Internacional Informática 2007. La Habana, febrero del 2007.

13. Supercursos en la red de salud Infomed. [homepage on the Internet; cited 2007 Aug 27]. Available from: www.supercurso.sld.cu/

14. Universidad Virtual de Salud. Sección de Estudio de Casos. [homepage on the Internet;cited 2007 Aug 27]. Available from: http://www.uvs sld.cu/clinica/casos/

15. Career focus, Briefing International Medical Edu cation Trust 2000. BMJ 2001;322:S3-7297 [cited
2006 May 13]. Available from: http://careerfocus. bmj.com/cgi/content/full/322/7297/S3-7297

16. Universidad Virtual de Salud. Discusión diagnóstica en Clínica Virtual. [homepage on the Internet; cited 2007 Aug 27]. Available from: www. uvirtual2.sld.cu/clinica/dd/index.php3/

17. Universidad Virtual de Salud. Preguntas a expertos en Clínica Virtual. [homepage on the Internet; cited 2007 Aug 27]. Available from: www. uvirtual2.sld.cu/clinica/expertos/index.php3/

18. Qué es Web 2.0. Boletín de la Sociedad de la Información: Tecnología e Innovación [cited 2007 Feb 22]. Available from: http://sociedaddelainformacion.telefonica.es/jsp/articulos/detalle. jsp?elem $=2146$

19. UNESCO. Oficina regional de Educación para América Latina y el Caribe. Modelo de gestión GESEDUCA. REPLAD, Santiago, Chile, 1994 [cited 2007 Aug 5]. Available from: http://www. unesco.cl/medios/biblioteca/documentos/modelo_gestion_geseduca.pdf

\section{THE AUTHOR}

José B. Jardines Méndez, Specialist in Public Health, Full Professor of Public Health and Ethics at the Higher Institute of Medical Sciences of Havana, and Assistant Professor and Member of the Scientific Council at the National School of Public Health, Havana. jardines@infomed.sld.cu 